\title{
Exploring the Digital Business Ecosystem of the Internet of Things in Emerging Economies with a Focus on the Role of Pseudo-Private Companies
}

\author{
Tahereh Saheb \\ Tarbiat Modares University, Tehran, Iran \\ t.saheb@modares.ac.ir
}

Faranak Hosseinpouli Mamaghani

Tarbiat Modares University, Tehran, Iran

\section{Abstract}

The Internet of Things (IoT) is one of the emerging drivers of the economy that transforms the business landscape and forms of collaboration and value creation. In this study, we performed a Delphi-based study to explore the digital business ecosystem (DBE) of IoT in emerging economies, focusing on power dynamics among actors, the processes of value co-creation, topologies, and critical success factors affecting the health of the ecosystem. We conducted two panels of a three-round Delphi study from 2017 through 2019 among Iranian IoT experts. This study identifies two types of the digital business ecosystems surrounding IoT in Iran. One type comprises only pseudo-private companies that have strong interactions with government organizations and state-owned banks. The other type of digital business ecosystem surrounding IoT technology comprises start-ups and private small and medium companies that have no interaction with pseudo-private companies. The interaction of start-ups and Small Medium Enterprises (SMEs) is mainly with universities. The study shows that pseudo-private companies play a dominant role in the Business to Business (B2B) and Business to Government (B2G) markets while SMEs and start-ups have a dominant role in the B2C market and promote creativity and innovation in the Business to Customer (B2C) market. This study extends the literature on digital business ecosystems with a focus on the health of the DBEs of IoT technologies and the potential for future innovation in the digital economy.

Keywords: Digital Business Ecosystem, Internet of Things, Emerging Economies, Co-Creation, Health of Business Ecosystem, Pseudo-Private Companies, Niche Creation

\section{Introduction}

The Internet of Things (IoT), as a flourishing digital technology, is one of the emerging drivers of the economy in many countries, transforming the business landscape and forms of collaboration and value creation (Selander et al., 2013). IoT refers to the network of small and intelligent devices that are widely distributed across geographic locations, are connected through the Internet, and have extended human sensing capabilities (Saheb \& Izadi, 2019).

The promising nature of IoT products and services has ignited a series of collaborative organizational networks, such as digital business ecosystems (DBE). IoT technologies not only connect a series of interacting objects together, but also include stakeholders who connect with IoT (Rong et al., 2015). In this study, we investigated the digital business ecosystem of the IoT. We define the business ecosystem as a loosely connected business community composed of various actors with a shared common goal who co-evolve with each other (Moore, 1993). The "Digital Business Ecosystem," as an extension of Moore's theory of business ecosystems, is also 
defined as a collaborative network in which digital technology plays a major role in developing economic communities of loosely-coupled organizations and individuals developing cross-industry collaborations and modes of value co-creation (Moore, 1993, 1996). As Mazhelis et al. (2012) define it, the digital business ecosystem surrounding the IoT technology, is a special type of digital business ecosystem composed of "the community of interacting companies and individuals along with their socio-economic environment, where the companies are competing and cooperating by utilizing a common set of core assets related to the interconnection of the physical world of things with the virtual world of Internet" (Mazhelis et al., 2012, p.5). The DBE of IoT is a sociotechnical environment composed of individuals, organizations, and digital technologies using collaborative and competitive interactions to form new modes of value co-creation by different entities within the ecosystem. As a collaborative network, the DBE of IoT is composed of various actors and entities in which traditional modes of value creation, collaboration and progress are disrupted to achieve a common goal (Ikävalko et al., 2018; Kar et al., 2018).

In this study, we did not limit our research to a specific industry and business ecosystems around that industry since collaborative interactions form the collection of actors of an ecosystem. Unlike traditional business settings, in an IoT-enabled digital business ecosystem, the process of value co-creation is facilitated through collaborative interactions between various actors and the business community (Leminen et al., 2015, 2012; Rong et al., 2015; Westerlund et al., 2014). In this research, we surveyed all companies that are registered as IoT companies regardless of the type of their industry. We defined an IoT company as a company that is involved in all five categories of hardware, middleware, software, presentation, and protocols and the use of these technologies to deliver products and services to consumers (Saheb \& Izadi, 2019). Inside the business ecosystem of IoT, many entrepreneurs have been developing new IoT products and services and establishing start-ups and companies around their ideas (Chuang, 2018); simultaneously, many large companies have been upgrading their legacy systems with IoT products and services (Jónasdóttir et al., 2018) and spending billions of dollars on the development of new IoT products. At the same time, governments provide policies (Lee, 2019) and financial and non-financial support of IoT ecosystems (Herweijer et al., 2018; Lee, 2019; Shin, 2019).

The digital business ecosystem theory has become pervasive in IT strategic management literature (Q. Sun et al., 2018); however, there is scant scholarly research regarding the health of a digital business ecosystem. Previous studies have mainly explored digital business ecosystems from the following perspectives: DBE network, DBE value co-creation, DBE collaboration, DBE knowledge management, and DBE strategy-making (Senyo et al., 2019). Little attention has been devoted to the health of IoT enabled digital business ecosystems in emerging markets concerning the four aspects of robustness, creativity, interoperability, and productivity. This paper proposes a theoretical perspective of the various components enriching or threatening the health of an IoT-enabled digital business ecosystem. The empirical case study for this paper is the DBE of the IoT in Iran. This research builds on existing knowledge in the fields of IT strategic management literature by extending the literature on the digital business ecosystem. The central issue addressed in this study is the DBE of the IoT ecosystem in Iran, and our results are based on a two-panel Delphi study and semi-structured interviews with IoT experts. 
The evaluation of key critical success factors within a digital business ecosystem through a qualitative study enables us to better explain the existence of varied actors, their complex interactions, and value creation processes. The current study fills the research gap on DBE health arguing that the critical success factor of a digital business ecosystem can be determined through measuring productivity, robustness, creativity, and interoperability, which provide new insights into the survival or bankruptcy of digital companies (Iansiti \& Levien, 2004a).

This study seeks to contribute to our current knowledge of IT strategic management in three ways, depicted in Figure 1: First, it extends our knowledge of IoT-enabled digital business ecosystems. The application of digital business ecosystem theory can further the theoretical reasoning. This theory concerns the complex interactions of actors that have particular roles, heterogeneous levels of control, and distinct degrees of contribution with interaction networks of value creation and innovation; these interactions occur in emerging economies inside business ecosystems centered on digital technologies. Prior research has identified different value structures and topologies in the US and Europe surrounding Information Communication Technology (ICT) (Corallo et al., 2017; Iansiti \& Levien, 2002). Furthermore, previous studies demonstrate how IoT business ecosystems develop in Europe and the US (e.g., Leminen et al., 2015; Westerlund et al., 2014). However, there is a paucity of scholarly attention on the DBE of IoT in emerging economies, and this study aspires to fill this research gap. Previous studies have explored the digital business ecosystem surrounding IoT technology in developed countries (e.g., Leminen et al., 2015, 2012; Rong et al., 2015; Westerlund et al., 2014). They have also incorporated the theory of business ecosystems, explaining the actors, roles, and value-creation processes without examining the critical success factor of an IoT business ecosystem. The present work aims to explore this marginalized area of the digital business ecosystem theory by conducting an empirical investigation of the IoT-enabled digital business ecosystem in an emerging economy with its unique socio-political and economic contexts. This study will unveil the differences and similarities between emerging economies and developed countries in terms of value cocreation processes, actors, roles, interactions, and power dynamics in the DBE of IoT. According to the GSMA, IoT connections in the Middle East region are expected to reach $1.1 \mathrm{bn}$ by 2025 (The Mobile Economy: Middle East and North Africa 2018, 2018). This report suggests that IoT revenue in the MENA region will increase at an average annual rate of $19 \%$ by 2025 to reach $\$ 55$ billion. The Iranian government has been pushing for more IoT infrastructure in the future since 2017 (Financial Tribune, 2017).

The second contribution of this study to the current knowledge of the digital business ecosystem is an analysis of four major critical success factors of a business ecosystem, i.e. robustness, productivity, interoperability, and creativity. Disruptive technologies are accompanied by uncertainties surrounding digital ecosystems (Rong et al., 2013) requiring the nurturing of ecosystems (Moore, 1996) and healthy networks of cooperative actors (Iansiti \& Levien, 2004b). Therefore, it is worth exploring how critical success factors explain the overall health of digital businesses and the behavior of enterprises and other actors. Previous studies recommend that the survival of a single enterprise interlinks with the survival of an ecosystem (Iansiti \& Levien, 2004b). Businesses are inclined toward developing networks of value-cocreation in which various actors, such as customers, partners, and producers, are integrated into mutually co-create values (Hein et al., 2019). To the best of the authors' knowledge, this is the first study exploring the health of an IoT enabled digital business ecosystem in an emerging economy. 
The third contribution of this study to the current knowledge on the digital business ecosystem is that it identifies a series of factors impacting the health of IoT business ecosystems in emerging economies from the perspective of experts. The Delphi study will enable the prediction of future scenarios of factors influencing the health of digital business ecosystems in emerging economies.
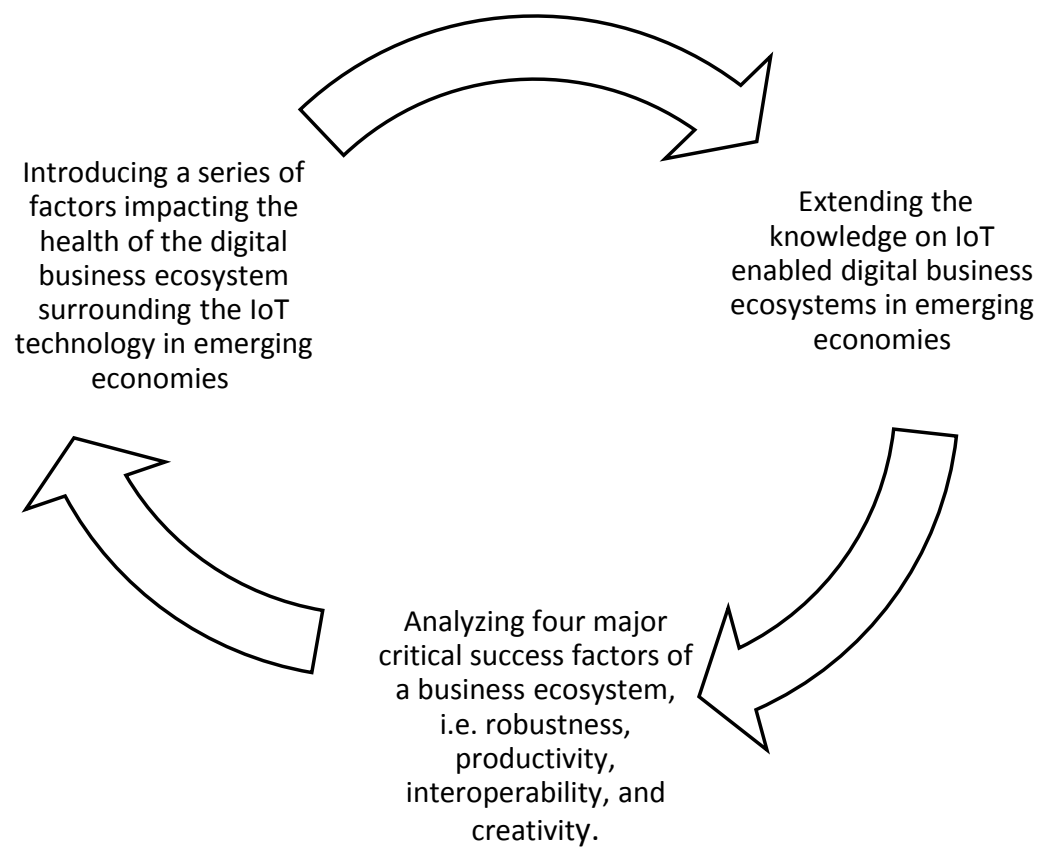

Figure 1. Theoretical Contributions of the Study

The structure of the paper is as follows: section 2 outlines the theoretical background of the study, Section 3 describes the research methodology used to unveil the findings of the study, reported in Section 4. Section 5 then concludes with a discussion of the study's contributions and limitations, and a consideration of possible future research topics.

\section{Theoretical Foundation}

\subsection{Digital Business Ecosystems}

A Digital Business Ecosystem is an extension of the business ecosystem theory (Moore, 1993). The DBE theory argues that digital technologies are one of the elements of a business ecosystem. Senyo et al. (2019) define a DBE as a sociotechnical environment composed of three elements of individuals, organizations, and digital technologies that develop collaborative and competitive relationships to co-create value through shared digital platforms. These elements transform into a single collection to support the survival of the technology. They achieve this goal by strengthening network effects, and they value co-creation strategies and harmonizing varying sources of intellectual capacity to improve the technology (Selander et al., 2013). Previous studies have analyzed varying aspects of a digital business ecosystem including DBE relationships and alliances, network analysis, value co-creation, DBE governance, legal issues, trust, risk and security, knowledge development, dissemination and management, and DBE strategies, processes, and management (Senyo et al., 2019). However, examining the health of 
digital business ecosystems remains unexplored. The existing DBE theory argues that business participants in a DBE collaborate with each other to promote innovation and to facilitate the process of value co-creation (L. Sun et al., 2016).

Prior research has mainly focused on the digital business ecosystem surrounding IoT technology models and the role of actors in Europe and the US (e.g. Leminen et al., 2015; Rong et al., 2015). Regarding the actors, their roles, and their interactions within the ecosystem, previous studies have demonstrated how different value structures and topologies are shaped in the US and Europe around ICT. In the US, the topology follows the Keystone model and has a hub-centered star structure. However, in Europe, it follows a flat model and has a flat mesh-like structure. In the US, the ecosystem is dominated by large hub firms, mainly private companies that hierarchically interact with numerous small firms. Alternatively, in Europe, the ecosystem consists of small and medium firms interacting in a non-hierarchical manner, without having a keystone or a dominator player (Corallo et al., 2017; Iansiti \& Levien, 2004b). Prior research has emphasized that business ecosystem strategies require a keystone to promote creativity and the health of niche players by increasing collective productivity, robustness, and diversity (Aksenova et al., 2018). Research has also investigated how and why tensions among competing values inside digital business ecosystems influence ecosystem relationships (Selander et al., 2010); as previous studies confirm, being a member of a digital business ecosystem generates new risks and uncertainties for firms as they delegate some control to the network (Adner, 2006; Iansiti \& Levien, 2004a).

\subsection{Business Ecosystem Health}

The theory of a business ecosystem has been extended by Iansiti \& Levien $(2002,2004 a)$ who define factors determining the health of a business ecosystem. They identify three determinants for productivity, five determinants for robustness, and two determinants for niche creation (Iansiti \& Levien, 2002, 2004a). The determinants of productivity are total factor productivity, productivity improvements, and the delivery of innovations. The determinants of robustness are survival rates, the persistence of structure, predictability, limited obsolescence, and continuity. Determinants of niche creation are variety and value creation (Iansiti \& Levien, 2002, 2004a).

To measure the robustness of an ecosystem (Iansiti and Levien, 2002, p.34), the theory incorporates: 1) the survival rate item to measure the number of bankrupt or start-up companies inside the ecosystem; 2) the persistence of ecosystem structure factor to measure the number of relations and agents that are subject to structural changes and external shocks; 3) the predictability item to measure the outbound links (an affiliation of a company to more than one business ecosystem); 4) the limited obsolescence factor to measure the change in the market share of technology; and 5) the continuity of the use experience item to measure the gradual changes of consumer experience of ecosystem products. To measure productivity (Iansiti and Levien, 2002, p. 36), the theory uses three determinants of 1) the total factor productivity variable to measure the productivity of participants in converting factors of production into value; 2 ) the productivity improvement factor to measure productivity over time; and 3) the delivery of innovation factor to measure whether the ecosystem effectively delivers new technologies, services, and ideas to its members. To measure niche creation (Iansiti and Levien, 2002, p 37), the theory uses two factors of 1) variety, to measure the variety of new services and options, and 2) value creation, to measure the overall value of new options created inside the ecosystem. In sum, based on this theory, robustness is the competency of an 
ecosystem to survive disruptions while productivity refers to the efficiency with which an ecosystem changes inputs into outputs and values. Niche creation is also defined as creating variety and novel competencies (Iansiti \& Levien, 2002).

\section{Research Methodology}

As depicted in Figure 2, in this study, we conducted two panels of a three-round Delphi study. The first panel was implemented from January 2017 to February 2018, and the second panel was implemented from May 2019 until August 2019. The Delphi study was selected because: 1) this method assists in collecting expert comments on a specific topic to reach a collective consensus over controversial or uncertain issues (von der Gracht, 2012); 2) this method has been previously incorporated in the IS literature to study digital technologies; 3) since the contributors to the study are well-informed about the digital business ecosystem surrounding IoT technology in Iran, their ideas can be beneficial (Linstone \& Turoff, 1975) and can address the questions of our study. To complement the results of our Delphi study (Keil et al., 2013), we also conducted a series of semi-structured interviews.

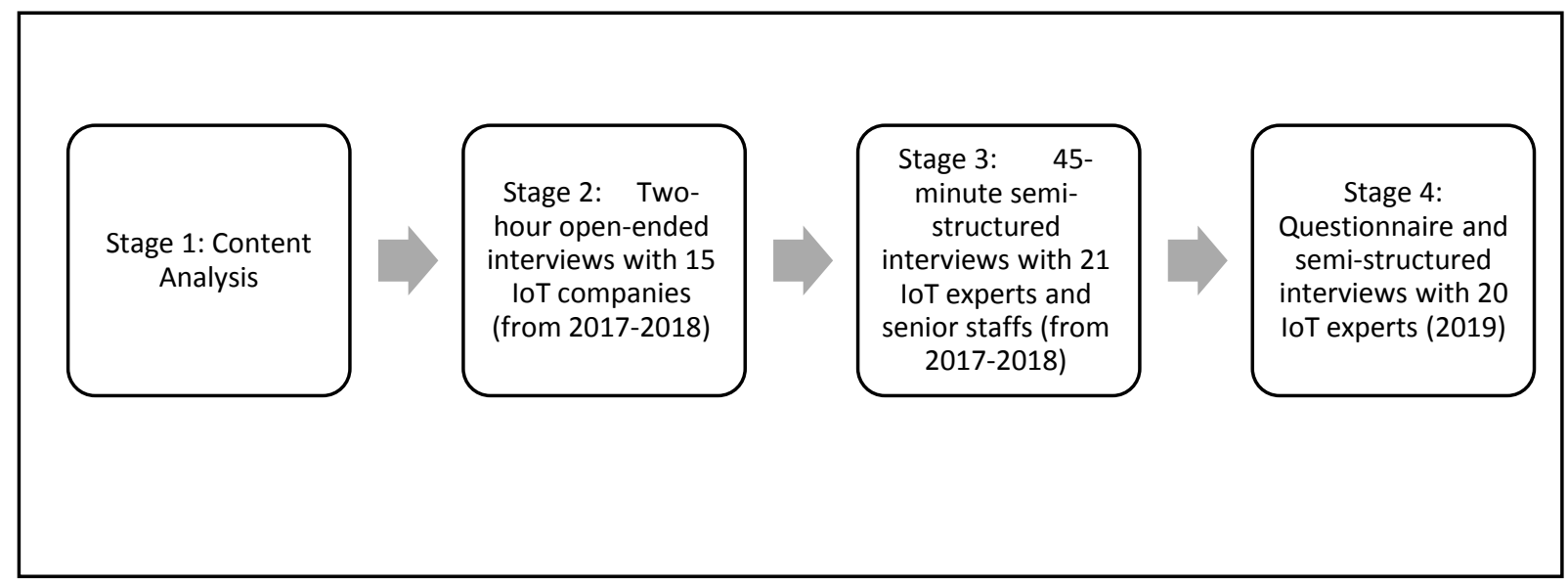

Figure 2. Research Steps of the Study

\subsection{First Panel of the Delphi study}

We collected empirical data from January 2017 to February 2018, consisting of a three-round Delphi study and content analysis. We chose the Delphi method with open-ended questions and semi-structured interviews. Based on national statistics for 2018, around 48 companies in Iran have registered as IoT companies, whose major mission is to deliver IoT products and services. Since that number was limited, we sent interview requests to all the companies, and only 15 companies agreed to be interviewed. Of this number, eight were start-ups, five were SMEs, and two were Pseudo-Private Companies (PPCs). Of the 15 companies included in the second round, only 12 companies agreed to participate in the study. All twelve companies attended the third round.

In the first round, we conducted two-hour open-ended interviews. We inquired about the following items:

1. The description of the IoT ecosystem in Iran

2. The factors influencing the performance of the system

3. The role of the interviewee's company within the ecosystem

4. The actors of the ecosystem and their roles 
5. The interaction and communication of the actors within the ecosystem

6. The networks and communities of the IoT ecosystem.

The Delphi study enabled us to naturally forecast unclear topics with no constraint on responses. We employed facilitated and interactive group communication meetings to solicit feedback from our experts including CEOs, marketing managers, business development managers, senior executive managers, and CTOs. After consolidating the feedback and returning it to each respondent individually, we asked the experts to revise their feedback to derive a forecast based on the groups' opinions. The participants remained anonymous, so nobody dominated the discussion. . We repeated the Delphi process in three rounds as we reached the stability of responses at this round. The semi-structured interviews at the second stage lasted for 45 minutes. The questions consisted of two parts: the first part was about the company's biography and its status in the ecosystem. The second part of the questions asked about the role of various actors within the ecosystem, the value creation process, the exchange of tangible and intangible assets in the ecosystem, and interactions with other actors and value networks. We asked the experts to elaborate on the IoT ecosystem summarized from the last round. In the third round, we also included the perspectives of senior staff members of the companies, and in total, 21 individuals attended the interviews.

\subsection{Second Panel of the Delphi Study}

We conducted the second panel from May 2019 to August 2019. We interviewed around 20 experts working with IoT companies in Iran. At this stage, we developed a questionnaire (Table 1) based on the business ecosystem theory (Moore, 1996), the theory of business ecosystem health by (Iansiti \& Levien, 2004a), and the results of the first panel

In regard to the administration of the Delphi questionnaire (Table 1), we designed some of the questions so that the experts could rate variables based on a 5-point numerical scale and some of the questions were designed so that the experts could choose from multiple items. We shared feedback of each round with each panellist and asked them to re-answer the questions until the panellists could reach a consensus. We calculated the mean rank, Kendall's W, Standard Deviation (SD), and frequency statistics.. In order to increase the reliability of the questionnaires, we pre-tested the questionnaire among a sample of respondents. We developed the questionnaire on the Café Pardazesh website in Farsi and sent a link to the experts via email and LinkedIn. One of the major elements of increasing the quality of results of Delphi studies is selecting a panel of appropriate experts (Paré et al., 2013). The identities of the experts remained anonymous to avoid affecting the respondents. In 2019, the number of IoT companies increased to 150 compared to 48 companies in 2018 . We sent the invitations to 40 companies, and 20 companies agreed to participate in our study. The experts were IT managers, marketing managers, CEOs, and R\&D managers with more than 3 years' experience. We then interviewed 10 IoT experts to complement the results of our Delphi study.

The questionnaire of the second panel was composed of seven sections designed to measure the actors, roles, interactions, value exchange, and health of the ecosystem. To design the questions on the "Roles," "Actors," "value exchange," and "Interactions," we incorporated the definitions of "keystone," "niche," and "dominator" as well as the business ecosystem theory introduced by (Iansiti \& Levien, 2004b; Moore, 1993). We derived questions to measure the health of the ecosystem (Parts A, B, and C) from the health of the ecosystem theory by (Iansiti \& Levien, 2002, 2004a). 


\begin{tabular}{|c|c|}
\hline Sections & Questions \\
\hline $\begin{array}{l}\text { Actors and Roles } \\
\text { (Part A, Multi-Item choice) }\end{array}$ & $\begin{array}{l}\text { 1- Which players control the ecosystem and do not produce value in the } \\
\text { ecosystem? } \\
\text { 2- Which players monitor the key activities of the ecosystem and co-create } \\
\text { value alongside the other actors? } \\
\text { 3- Which players are major innovators of the ecosystem and produce } \\
\text { value regarding specific and niche topics? } \\
\text { Items: } \\
\text { a) Start-ups } \\
\text { b) Pseudo-private companies } \\
\text { c) Regulatory bodies } \\
\text { d) SMEs; } \\
\text { e) Public companies } \\
\text { f) consumers } \\
\text { g) others, please specify }\end{array}$ \\
\hline $\begin{array}{l}\text { Actors and Roles } \\
\text { (Part B, Multi-Item choice) }\end{array}$ & $\begin{array}{l}\text { 1- What is the role of pseudo-private companies (PPCs) inside the IoT } \\
\text { ecosystem? } \\
\text { 2- What is the role of regulatory bodies inside the IoT ecosystem? } \\
\text { 4- What is the role of start-ups inside the IoT ecosystem? } \\
\text { Items: What is the role of SMEs inside the IoT ecosystem? } \\
\text { a) Short-term, to gain benefit without creating value inside the } \\
\text { b) To share knowledge and physical assets } \\
\text { c) To establish continuous interaction with other actors to support } \\
\text { d) To encourage innovation and creativity } \\
\text { e) To control the market and cycle of value network }\end{array}$ \\
\hline $\begin{array}{l}\text { Interactions } \\
\text { (Ranking from very bad to } \\
\text { very good) }\end{array}$ & $\begin{array}{l}\text { 1- From a general perspective, how do you estimate the relationship of } \\
\text { Items: } \\
\text { actors inside the ecosystem? } \\
\text { a) Very bad: Relationships are inappropriate or ineffective. Actors only } \\
\text { take advantage of each other. } \\
\text { b) Bad: No outcomes are expected from relationships. Management is } \\
\text { weak and inefficient. Based on lobbying and favoritism. } \\
\text { c) Good: Relationships produce good results, and actors are stronger than } \\
\text { they were in the past. } \\
\text { d) Very Good: Ongoing and lasting relationships produce good value for } \\
\text { all shareholders. Other ecosystem actors improve each other's } \\
\text { performance. }\end{array}$ \\
\hline $\begin{array}{l}\text { Health of the ecosystem } \\
\text { (Part A) } \\
\text { (Ranking from Very High } \\
\text { to Very Low) }\end{array}$ & $\begin{array}{l}\text { How do you evaluate the health of the digital business ecosystem surrounding IoT } \\
\text { technology in Iran? } \\
\text { 1- There are continuous and consistent interactions among the actors of } \\
\text { the ecosystem. } \\
\text { 2- There is a continuous knowledge flow among the actors. } \\
\text { 3- The environment of the ecosystem is promoting innovation and } \\
\text { creativity. } \\
\text { 4- The actors encourage each other to be efficient and effective. }\end{array}$ \\
\hline $\begin{array}{l}\text { Health of the ecosystem } \\
\text { (Part B) } \\
\text { (Ranking from strongly } \\
\text { agree to strongly disagree) }\end{array}$ & $\begin{array}{l}\text { Do you agree or disagree with the following statements? } \\
\text { a. Robustness of the Ecosystem } \\
\text { 1. The number of successful IoT start-ups is increasing inside the } \\
\text { IoT ecosystem in Iran (Survival Rates). }\end{array}$ \\
\hline
\end{tabular}




\begin{tabular}{|c|c|}
\hline & $\begin{array}{l}\text { 2. The number of relations and agents is subject to structural } \\
\text { changes (Persistence of ecosystem structure). } \\
\text { 3. Actors of the digital business ecosystem surrounding IoT } \\
\text { technology belong to other business ecosystems and offer } \\
\text { other services and products as well (Predictability of } \\
\text { remaining in the ecosystem through outbound links). } \\
\text { 4. Changes in the market share of IoT depend on the diffusion of } \\
\text { innovation (Limited obsolescence). } \\
\text { 5. Consumer experience is evolving in response to the } \\
\text { introduction of new technologies (Continuity of user } \\
\text { experience). } \\
\text { b. Productivity } \\
\text { 1. There are relations between the amount of labor and capital } \\
\text { employed and the additional value created (total } \\
\text { productivity). } \\
\text { 2. The productivity of firms is gradually improving (productivity } \\
\text { improvement). } \\
\text { 3. The members of the ecosystem can deliver innovation } \\
\text { capabilities with no restriction and barrier (Delivery of } \\
\text { innovations). } \\
\text { a) Niche Creation } \\
\text { 1) The number of new options, technological building blocks, categories, } \\
\text { and products is varied (Variety) } \\
\text { 2) IoT technologies have created an increasing value inside the ecosystem } \\
\text { (Value creation). }\end{array}$ \\
\hline $\begin{array}{l}\text { Health of the ecosystem } \\
\text { (Part C) } \\
\text { (Ranking from very } \\
\text { important to unimportant) }\end{array}$ & $\begin{array}{l}\text { Please rate the importance of the following factors in increasing the health of } \\
\text { digital business ecosystem surrounding IoT technology in Iran. } \\
\begin{array}{ll}\text { 1- } & \text { Integrated communication } \\
2- & \text { Standardization } \\
3- & \text { Transparency } \\
4- & \text { Trust } \\
5- & \text { Knowledge sharing } \\
\text { 6- } & \text { Economic collaborations } \\
\text { 7- } & \text { Re-engineering of business and organizational culture } \\
\text { 8- } & \text { Comprehensive regulations and their implementation } \\
\text { 9- } & \text { Security of the ecosystem } \\
\text { 10- } & \text { Educational programs }\end{array}\end{array}$ \\
\hline
\end{tabular}

Table 1. Questions asked in the second panel

\section{Results}

\subsection{Results of the Interviews}

In this part of the paper, we answer the following questions, asked in the first round of the study: Who are the major actors and what roles do they play inside the ecosystem? What values do they exchange? How do the actors contribute to the evolution and foundational structure of the Iranian IoT industry? We have organized our analysis based on the pillars of value network offered by (Westerlund et al., 2014).

\subsubsection{Value Nodes and Drivers}

The experts of the first round identified five major actors inside the ecosystem: pseudo-private companies (PPCs), start-ups, SMEs, consumers, and the government. The analysis of the interviews shows that the most dominant actor in the DBE of IoT in Iran is PPCs, which are called Qosoo-lati in Farsi. Qosoo-lati is a private company that is mainly managed by the players who formerly worked in the state or are currently working in the state. The consensus 
was that most of the PPCs violate the law of commerce to limit the activities of SMEs and startups, and to dominate the IoT market. The experts reported that these actors dominate the B2B and B2G markets and their main interaction is with the government. The experts described the PPCs as "dominators" that do not create any shared value (value driver pillar) and focus mainly on the monetary benefits of their own companies without creating any shared tangible and intangible values for the other nodes.

\begin{tabular}{|c|c|}
\hline $\begin{array}{l}\text { Current stage of digital } \\
\text { business ecosystem } \\
\text { surrounding IoT technology }\end{array}$ & $\begin{array}{l}\text { The stage is emerging: Most IoT companies have registered during the last } \\
\text { three years; most of them have not engaging and dynamic websites. There } \\
\text { is a lack of transparency in reporting the annual activities and statistics of } \\
\text { enterprises particularly the PPCs. }\end{array}$ \\
\hline Actors & $\begin{array}{l}\text { Dominator Actors: Pseudo-Private Companies } \\
\text { Niche Actors: SMEs, Start-ups } \\
\text { Keystone Player: No keystone player }\end{array}$ \\
\hline $\begin{array}{l}\text { Intention of the start-ups and } \\
\text { SEMs to enter the IoT } \\
\text { ecosystem }\end{array}$ & $\begin{array}{l}\text { Major incentives: Monetary reasons, and desire to improve operational and } \\
\text { management processes, interaction with other value nodes, and decision- } \\
\text { making } \\
\text { Minor incentives: Desire to improve interactions with the customers and } \\
\text { sustainability }\end{array}$ \\
\hline $\begin{array}{l}\text { Intention of the PPCs to enter } \\
\text { the IoT ecosystem }\end{array}$ & $\begin{array}{l}\text { Major incentive: Need to exploit knowledge and expertise } \\
\text { Minor incentives: Desire to improve interaction with the other value nodes } \\
\text { and with the customers, and desire to promote shared values such as } \\
\text { sustainability }\end{array}$ \\
\hline $\begin{array}{l}\text { Interaction of start-ups and } \\
\text { SMEs with }\end{array}$ & $\begin{array}{l}\text { The most interaction with: Private financial networks } \\
\text { The least interaction with: State networks and research institutions }\end{array}$ \\
\hline Interaction of PPCs with & $\begin{array}{l}\text { The most interaction with: Government and other PPCs } \\
\text { The least interaction with: Start-ups and SMEs }\end{array}$ \\
\hline $\begin{array}{l}\text { The major customer of start- } \\
\text { ups and SMEs }\end{array}$ & The General public (B2C) \\
\hline The major customer of PPCs & Government organizations and industries (B2B and B2G) \\
\hline $\begin{array}{l}\text { Challenges that the start-ups } \\
\text { and SMEs face }\end{array}$ & $\begin{array}{l}\text { Lobbying by the PPCs } \\
\text { Legal restrictions } \\
\text { Lack of universal standards } \\
\text { Lack of access to external data resources } \\
\text { Consumers' lack of trust } \\
\text { Lack of a unified platform for sharing IoT data } \\
\text { Weak collaboration among the IoT companies with the other actors, especially } \\
\text { the networks } \\
\text { Need for re-engineering of business models and organizational culture } \\
\text { Lack of comprehensive regulations } \\
\text { Lack of security of the ecosystem } \\
\text { Lack of prosumers as there are only consumers of IoT products and services }\end{array}$ \\
\hline
\end{tabular}

Table 2. Intention to enter, interaction with the other actors, and challenges that start-ups and SMEs face within the IoT ecosystem

The experts reported that the SMEs and start-ups are the most active networks within the ecosystem and have the most effective interactions. The experts believed that the greatest interaction of the IoT SMEs and start-ups is with the financial entities and banks to receive financial support.

They also believed that networks composed of accelerators and innovation hubs have the least impact on the ecosystem. According to the experts, the Iranian digital business ecosystem surrounding IoT technology is not agile and volatile and lacks a fierce competition among the 
nodes. The experts linked the situation to the dominance of PPCs inside the IoT market. The experts identified a series of legal, business, data, and security factors that have negatively impacted the health and performance of the IoT business ecosystem. These factors are summarized in Table 2. Regarding the role of the government, most experts reached a consensus that the government's major role has been the commercialization of ideas, products, services.

\subsubsection{Value Structure (Topology)}

Analysis of the experts' opinions shows that the topology of the digital business ecosystem surrounding IoT technology in Iran (Table 3) is composed of two major categories of players: the dominator players, who are a few large pseudo-private companies controlling the $\mathrm{B} 2 \mathrm{G}$ and B2B markets, and the start-ups and SMEs mainly controlling the B2C market. The experts identified the PPCs as the dominator actors, and SMEs and start-ups as niche companies dominating the $\mathrm{B} 2 \mathrm{C}$ market. The study shows that the ecosystem lacks a keystone player. The study also shows that the public is only comprised of the buyers and consumers of IoT products that do not co-create any value in the ecosystem. So there is no "prosumer" and the ecosystem lacks "co-creation" of values by the consumers.

\begin{tabular}{|l|l|l|}
\hline Context & Topology & Major Category of Players \\
\hline US & $\begin{array}{l}\text { Keystone model and has a } \\
\text { hub-centered star structure }\end{array}$ & $\begin{array}{l}\text { A large hub firm composed of private companies that interact with } \\
\text { a large number of small suppliers }\end{array}$ \\
\hline Iran & Flat mesh-like structure & $\begin{array}{l}\text { Small and medium firms interact in a non-hierarchical manner, } \\
\text { without a keystone or dominator player. }\end{array}$ \\
\hline $\begin{array}{l}\text { We identified two major players: The first category of players is } \\
\text { composed of a limited number of large PPCs dominating the } \\
\text { business ecosystem of IoT, and controlling the B2G and B2B markets. } \\
\text { These actors are called dominators. The other category of players } \\
\text { consists of niche companies delivering IoT products to the public } \\
\text { and controlling the B2C market. They are called niche players. The } \\
\text { ecosystem lacks keystone players and value co-creation. Interaction } \\
\text { among the silos is non-hierarchical. }\end{array}$ \\
\hline
\end{tabular}

Table 3. Comparison of value structures (topologies) in various contexts

\subsubsection{Value Exchange and Extract}

In this section, we describe value exchanges and value extracts among the actors. Regarding the tangible values that SMEs and start-ups deliver to the ecosystem, most of the experts mentioned the IoT hardware and devices as the main value. Most experts have referred to SMEs and start-ups as "thing providers" of IoT products and devices. The most value delivered in the ecosystem is the company's annual reports, mainly delivered at major exhibitions. The annual reports are summaries of the company's activities that are not available online. This limited access hinders transparency, accountability, and the public's right to access to data. The reports do not convey expertise and knowledge and are composed mainly of statistical information, and most of the content on the companies' websites is pure information and news. The websites of IoT companies do not provide digital platforms for social interaction, engagement of actors, and knowledge sharing.

Regarding the tangible value that the IoT PPCs deliver, the experts argued that the PPCs act within their silos with no value exchange or interaction with other SMEs and start-ups. The major interaction of the PPCs is with the government and large corporations and organizations. The experts believed, as one expert wrote, "the PPCs just extract knowledge 
and experience from other IoT companies without delivering anything into the ecosystem." The study shows that one of the major features of the digital business ecosystem surrounding IoT technology is the lack of partnerships among partners. Our analysis of the interviews shows that while the PPCs have not initiated partnerships with SMEs or start-ups, start-ups and SMEs have also shown little interest in partnerships with other SMEs and start-ups. Most experts believe that the least powerful roles within the IoT ecosystem belong to the cloud and big data providers, and this is because of the lack of service-centered logic in the ecosystem: "the ecosystem lacks cloud-based platforms to share data and other services with each other. The only service that SMEs and start-ups can offer is mobile applications for IoT devices," said one of the experts. This study shows that most IoT SMEs deliver IoT products, mainly hardware and devices with no value-added services, such as big data-based services.

The experts mentioned that the lack of strong competition in the market, weak infrastructures such as the weak role of cloud services, and dominance of PPCs in the B2B and B2G markets have forced the IoT SMEs and start-ups into the traditional business model of selling goods: "The main business models of most IoT SMEs and start-ups are distributing or importing IoT devices, and developing a mobile app as the value-added of their devices, mainly for the public to be used in smart buildings." Products and services are delivered with a "fixed price" revenue stream. The experts mentioned the lack of effort inside the B2C market to deliver value-added services for IoT products, and the fact that IoT SMEs and start-ups operate product-centered businesses. Most IoT companies define themselves as "sellers of IoT devices" or "thing providers." Ironically, the experts mentioned the urgent need to re-engineer their business models and monetization methods, but they limited their roles to traditional sellers of IoT devices, and considered developing an organizational vision and enterprise architecture as a "null and useless" effort to succeed in the ecosystem.

The current study demonstrates the lack of interest among IoT SMEs and start-ups in developing meaningful interactive and engaging social communities around IoT products. As a result, the chances that SMEs and start-ups will be able to extract value have been reduced and IoT products and services are not customized based on the perspectives of the consumers. For instance, one of the experts mentioned this fact by arguing that, "At this stage, we can't customize products based on the requests of our customers. We do not think communities around IoT can deliver us meaningful information about the behavior and requests of the customers." The experts noted that the IoT products that SMEs or start-ups deliver to the market "are not designed to offer too much choice for consumers." Lack of proliferation of choices is due to the actors' disbelief in social media and the value of opinions expressed through social networks: "Social networks are full of unsatisfied customers nagging each other about the delivery process of their devices, and not the product itself." To the experts, the IoT ecosystem in Iran is still in its early stages, and since funding and budget are very limited, the IoT products are "a fixed set of features," and SMEs and start-ups cannot offer highly customized products.

\subsection{Results of the Delphi Study}

In this section, we describe the results of the Delphi study to explore the health of the digital business ecosystem surrounding IoT technology based on the perspectives of experts. 


\subsubsection{Actors and Roles}

Regarding the keystone, niche, and dominator actors, Table 4 shows that in round 3, the experts reached a consensus regarding PPCs as actors controlling the DBE of IoT (with 85\% agreement, $.366=\mathrm{SD}$ and 1.85= Mean) (table shows only the top-selected items). The results show that SMEs are keystone players (90\% agreement, .308= SD and 2.90= Mean), and startups are niche players (95\% agreement, .224= SD, and 3.95=Mean) inside the ecosystem. With regard to the roles of PPCs, regulatory bodies, start-ups, and SMEs, as Table 4 shows, the main role of PPCs and the regulatory bodies is controlling the market (95\% agreement, .224= SD; and 4.95=Mean), while the role of start-ups, with a high SD, is sharing knowledge and encouraging innovation ( $50 \%$ agreement, $1.026=\mathrm{SD}$, and 3.00=Mean). The role of SMEs is also continuous interaction with other actors to support and monitor them $(85 \%$ agreement, $.366=$ $\mathrm{SD}$, and $2.85=$ Mean).

\begin{tabular}{|c|c|c|c|c|c|c|c|c|c|}
\hline \multirow[t]{2}{*}{ Questions } & \multicolumn{3}{|l|}{ Round 1} & \multicolumn{3}{|l|}{ Round 2} & \multicolumn{3}{|l|}{ Round 3} \\
\hline & Percentage & $S D$ & Mean & Percentage & $S D$ & Mean & Percentage & $S D$ & Mean \\
\hline \multicolumn{10}{|c|}{ Which players control, or monitor, or major innovators inside the ecosystem? } \\
\hline $\begin{array}{l}\text { Dominators } \\
\text { (Control) }\end{array}$ & & 1.761 & 2.45 & & .470 & 1.70 & & .366 & 1.85 \\
\hline 1- PPCs & 40 & & & 70 & & & 85 & & \\
\hline $\begin{array}{ll}2- & \text { Regulatory } \\
& \text { Bodies }\end{array}$ & 35 & & & 30 & & & 15 & & \\
\hline $\begin{array}{ll}\text { 3- } & \text { Public } \\
& \text { Organizations }\end{array}$ & 15 & & & 0 & & & 0 & & \\
\hline Keystones (Monitor) & & .759 & 3.45 & & .562 & 2.90 & & .308 & 2.90 \\
\hline 1- SMEs & 55 & & & 85 & & & 90 & & \\
\hline 2- Start-ups & 30 & & & 0 & & & 0 & & \\
\hline 3- PPCs & 5 & & & 10 & & & 10 & & \\
\hline Niche (Innovator) & & .718 & 3.90 & & .410 & 3.80 & & .224 & 3.95 \\
\hline 1- Start-ups & 80 & & & 80 & & & 95 & & \\
\hline 2- SMEs & 10 & & & 20 & & & 5 & & \\
\hline \multicolumn{10}{|c|}{ What is the role of PPCs, regulatory bodies, start-ups and SMEs? } \\
\hline PPCs & & 1.773 & 2.75 & & .410 & 4.80 & & .224 & 4.95 \\
\hline 1- Short term & 45 & & & 20 & & & 5 & & \\
\hline $\begin{array}{ll}2- & \text { Encouraging } \\
\text { innovation }\end{array}$ & 20 & & & 0 & & & 0 & & \\
\hline 3- Control market & 25 & & & 80 & & & 95 & & \\
\hline Regulatory Bodies & & 1.556 & 4.00 & & .410 & 4.80 & & .224 & 4.95 \\
\hline 1- Short term & 15 & & & 0 & & & 5 & & \\
\hline $\begin{array}{l}\text { 2- Encourage } \\
\text { innovation }\end{array}$ & 5 & & & 20 & & & 0 & & \\
\hline 3- Control market & 65 & & & 80 & & & 95 & & \\
\hline Start-ups & & 1.234 & 2.45 & & 1.161 & 2.25 & & 1.026 & 3.00 \\
\hline 1- Short term & 25 & & & 30 & & & 0 & & \\
\hline 2- Share knowledge & 40 & & & 40 & & & 50 & & \\
\hline $\begin{array}{ll}\text { 3- } & \text { Encourage } \\
\text { innovation }\end{array}$ & 35 & & & 25 & & & 50 & & \\
\hline SMEs & & 1.482 & 2.75 & & .827 & 1.50 & & .366 & 2.85 \\
\hline 1- Short term & 30 & & & 20 & & & 5 & & \\
\hline 2- Share knowledge & 10 & & & 10 & & & 10 & & \\
\hline $\begin{array}{ll}\text { 3- } & \text { Continuous } \\
& \text { interaction }\end{array}$ & 35 & & & 70 & & & 85 & & \\
\hline Respondents number (N) & 20 & & & 20 & & & 20 & & \\
\hline
\end{tabular}


Table 4. Results of the experts' consensus regarding the actors and their roles inside the IoT business ecosystem

\subsubsection{Interaction of Actors}

With regard to the interactions, as Table 5 shows, the experts reached a consensus in the third round that the relationship of actors is "Bad" (85\% agreement, .366= SD, and 1.85= Mean). meaning that no outcomes are expected from relationships, and that management is weak and inefficient and is based on lobbying and favoritism.

\begin{tabular}{|c|c|c|c|c|c|c|c|c|c|}
\hline \multirow[t]{2}{*}{ Questions } & \multicolumn{3}{|l|}{ Round 1} & \multicolumn{3}{|l|}{ Round 2} & \multicolumn{3}{|l|}{ Round 3} \\
\hline & Percentage & SD & Mean & Percentage & SD & Mean & Percentage & SD & Mean \\
\hline \multicolumn{10}{|c|}{ From a general perspective, how do you estimate the relationship of actors inside the ecosystem? } \\
\hline & & .759 & 2.05 & & .444 & 1.75 & & .366 & 1.85 \\
\hline Very Bad & 25 & & & 25 & & & 15 & & \\
\hline Bad & 45 & & & 75 & & & 85 & & \\
\hline Good & 30 & & & 0 & & & 0 & & \\
\hline
\end{tabular}

Table 5. Interaction of the actors inside the ecosystem

\subsubsection{Health of the Ecosystem}

We initiated our inquiry regarding the health of the ecosystem with a general question: How do you evaluate the health of the digital business ecosystem surrounding IoT technology in Iran? As Table 6 shows, the experts reached a consensus that there is low continuous and consistent interaction among the actors (90\% agreement, .308=SD; and 4.10= Mean), and the level of continuous knowledge flow among the actors is low as well (90\% agreement, .308=SD; and $4.10=$ Mean) (the table shows only the top three options). The study also shows that the environment of the ecosystem in promoting innovation and creativity is at a low level $(70 \%$ agreement; .470=SD; and 3.70=Mean), and the level of encouragement by actors to be efficient and effective is low as well (70\% agreement; .470=SD; and 3.70=Mean).

\begin{tabular}{|c|c|c|c|c|c|c|c|c|c|}
\hline \multirow[t]{2}{*}{ Questions } & \multicolumn{3}{|l|}{ Round 1} & \multicolumn{3}{|l|}{ Round 2} & \multicolumn{3}{|l|}{ Round 3} \\
\hline & Percentage & SD & Mean & Percentage & $\mathrm{SD}$ & Mean & Percentage & SD & Mean \\
\hline \multicolumn{10}{|c|}{ How do you evaluate the health of digital business ecosystem surrounding IoT technology in Iran? } \\
\hline $\begin{array}{l}\text { Continuous } \\
\text { interaction }\end{array}$ & & .875 & 4.15 & & .686 & 3.95 & & .308 & 4.10 \\
\hline 1. Average & 30 & & & 10 & & & 0 & & \\
\hline 2. Low & 25 & & & 70 & & & 90 & & \\
\hline 3. Very Low & 45 & & & 15 & & & 10 & & \\
\hline $\begin{array}{l}\text { Continuous } \\
\text { knowledge flow }\end{array}$ & & .826 & 3.95 & & .887 & 3.95 & & .308 & 4.10 \\
\hline 1- Average & 35 & & & 10 & & & 0 & & \\
\hline 2- Low & 35 & & & 55 & & & 90 & & \\
\hline 3- Very Low & 30 & & & 25 & & & 10 & & \\
\hline $\begin{array}{l}\text { Encouraging } \\
\text { Atmosphere }\end{array}$ & & .865 & 3.70 & & .718 & 4.10 & & .470 & 3.70 \\
\hline 1- Average & 25 & & & 5 & & & 30 & & \\
\hline 2- Low & 50 & & & 65 & & & 70 & & \\
\hline 3- Very Low & 15 & & & 25 & & & 0 & & \\
\hline Promoting innovation & & 1.040 & 3.65 & & 1.046 & 3.60 & & .470 & 3.70 \\
\hline 1- Average & 30 & & & 20 & & & 30 & & \\
\hline 2- Low & 30 & & & 50 & & & 70 & & \\
\hline
\end{tabular}


Table 6. Results of the experts' opinions regarding the overall health of the IoT ecosystem

We also measured the health of the ecosystem based on the determinants of robustness, productivity, and niche creation. The experts rated the statements from "strongly agree" to "strongly disagree." Table 7 shows the combined percentage of "Strongly Agree" and "Agree" and the combined percentage of "Strongly Disagree" and "Disagree" for each factor for each round.

\begin{tabular}{|c|c|c|c|c|c|c|c|c|c|}
\hline \multirow{2}{*}{ Question } & \multicolumn{3}{|l|}{ Round 1} & \multicolumn{3}{|l|}{ Round 2} & \multicolumn{3}{|l|}{ Round 3} \\
\hline & Percentage & $S D$ & Mean & Percentage & $S D$ & Mean & Percentage & $S D$ & Mean \\
\hline \multicolumn{10}{|l|}{ Robustness } \\
\hline 1- Survival rate & $\begin{array}{l}\text { Agree: } 60 \\
\text { Disagree:30 }\end{array}$ & 1.234 & 2.55 & $\begin{array}{l}50 \\
45\end{array}$ & 1.210 & 2.90 & $\begin{array}{l}60 \\
40\end{array}$ & 1.050 & 2.95 \\
\hline $\begin{array}{ll}2- & \begin{array}{l}\text { Persistence of } \\
\text { ecosystem } \\
\text { structure }\end{array} \\
\end{array}$ & $\begin{array}{l}55 \\
20\end{array}$ & .883 & 2.60 & $\begin{array}{l}65 \\
35\end{array}$ & 1.040 & 2.65 & $\begin{array}{l}85 \\
15\end{array}$ & .759 & 2.45 \\
\hline 3- Predictability & $\begin{array}{l}90 \\
10\end{array}$ & .910 & 1.75 & $\begin{array}{l}75 \\
25 \\
\end{array}$ & .995 & 2.40 & $\begin{array}{l}90 \\
10\end{array}$ & .650 & 2.05 \\
\hline $\begin{array}{ll}4- & \begin{array}{l}\text { Limited } \\
\text { obsolescence }\end{array} \\
\end{array}$ & $\begin{array}{l}70 \\
5 \\
\end{array}$ & .813 & 2.15 & $\begin{array}{l}55 \\
45 \\
\end{array}$ & 1.089 & 2.85 & $\begin{array}{l}55 \\
20 \\
\end{array}$ & 988 & 2.65 \\
\hline $\begin{array}{ll}\text { 5- } & \text { Continuity of } \\
& \text { use experience }\end{array}$ & $\begin{array}{l}85 \\
15 \\
\end{array}$ & .912 & 2.10 & $\begin{array}{l}65 \\
35 \\
\end{array}$ & 1.192 & 2.50 & $\begin{array}{l}75 \\
10\end{array}$ & .967 & 2.25 \\
\hline \multicolumn{10}{|l|}{ Productivity } \\
\hline $\begin{array}{ll}\text { 1- } & \begin{array}{l}\text { Total } \\
\text { productivity }\end{array} \\
\end{array}$ & $\begin{array}{l}55 \\
25\end{array}$ & 1.273 & 2.60 & $\begin{array}{l}55 \\
40\end{array}$ & 1.210 & 2.90 & $\begin{array}{l}65 \\
15\end{array}$ & .882 & 2.40 \\
\hline $\begin{array}{ll}2- & \begin{array}{l}\text { Productivity } \\
\text { improvement }\end{array} \\
\end{array}$ & $\begin{array}{l}65 \\
20 \\
\end{array}$ & 1.276 & 2.55 & $\begin{array}{l}55 \\
45 \\
\end{array}$ & 1.099 & 2.95 & $\begin{array}{l}60 \\
40 \\
\end{array}$ & 1.071 & 2.90 \\
\hline 3- $\begin{array}{l}\text { Delivery of } \\
\text { innovations }\end{array}$ & $\begin{array}{l}50 \\
50\end{array}$ & 1.572 & 3.05 & $\begin{array}{l}45 \\
55\end{array}$ & 1.099 & 3.05 & $\begin{array}{l}25 \\
60\end{array}$ & .998 & 3.45 \\
\hline \multicolumn{10}{|l|}{ Niche Creation } \\
\hline 1- Variety & $\begin{array}{c}65 \\
30\end{array}$ & 1.410 & 2.25 & $\begin{array}{l}65 \\
35 \\
\end{array}$ & 1.192 & 3.05 & $\begin{array}{l}60 \\
30\end{array}$ & 1.137 & 2.65 \\
\hline 2- Value Creation & $\begin{array}{r}50 \\
20\end{array}$ & 1.231 & 2.60 & $\begin{array}{l}55 \\
40 \\
\end{array}$ & 1.192 & 2.50 & $\begin{array}{l}40 \\
60 \\
\end{array}$ & .945 & 2.95 \\
\hline $\begin{array}{l}\text { Respondents number } \\
\text { (N) }\end{array}$ & \multicolumn{3}{|l|}{20} & \multicolumn{3}{|l|}{20} & \multicolumn{3}{|l|}{20} \\
\hline
\end{tabular}

Table 7. Results of the experts' consensus regarding the critical success factors of IoT ecosystem

Concerning the robustness of the ecosystem, as Table 7 shows, $60 \%$ of the experts agreed that the number of successful IoT start-ups is increasing inside the IoT ecosystem in Iran; 85\% believed that the number of relations and agents is subject to structural changes; $90 \%$ argued that actors of the digital business ecosystem surrounding IoT technology belong to other business ecosystems and offer other services and products as well; $55 \%$ affirmed that changes in the market share of IoT depend on the diffusion of innovation; and 75\% claimed that consumers experience is evolving in response to the introduction of new technologies. In total, half of the experts reached a consensus that the digital business ecosystem surrounding IoT technology in Iran is robust.

Regarding the productivity of the ecosystem, $65 \%$ of the experts agreed that there are relationships between the amount of labor and capital employed and the additional value created, while $60 \%$ of the experts claimed that the productivity of firms is gradually 
improving. Concerning the delivery of innovations, only $25 \%$ believed that the members of the ecosystem can deliver innovation capabilities with no restrictions, and $60 \%$ claimed otherwise. In total, around $50 \%$ of the experts believed that the digital business ecosystem surrounding IoT technology in Iran is productive.

Concerning niche creation, $60 \%$ believed that the number of new options, technological building blocks, categories, and products is varied, and only $40 \%$ believed that IoT technologies have created increasing value within the ecosystem. In sum, around $50 \%$ of the experts reached a consensus that the digital business ecosystem surrounding IoT technology has niche creation competencies.

In the third step in measuring the health of IoT business ecosystem, we asked the experts to rate the importance of a series of the factors impacting the health of the digital business ecosystem surrounding IoT technology in Iran. These items were highly referenced by the experts in the first panel. We consolidated the list and extracted 10 highly- referenced factors. In this part, we measured the rank, Kendall's W, and Standard Deviation (SD) of each item. As Table 8 shows, in the first round, 20 IoT experts filled out the items. The most important items were integrated communication among the actors, educational programs, job security, IoT regulations, and standardization (mean rank $>1.50$ ). The study shows that the highest standard deviation was .489 for the economic collaboration item and .470 for the trust option. This high SD shows the lack of consensus among the experts. The final Kendall's W score is . 479 showing a moderate degree of consensus among the experts.

\begin{tabular}{|c|c|c|c|c|c|c|c|c|c|}
\hline \multirow{2}{*}{ Items } & \multicolumn{3}{|c|}{ Round 1} & \multicolumn{3}{|c|}{ Round 2} & \multicolumn{3}{|c|}{ Round 3} \\
\hline & Mean & $S D$ & Rank & Mean & $S D$ & Rank & Mean & $S D$ & Rank \\
\hline Integrated Communication & 1.30 & .470 & 7 & 2.05 & .686 & 1 & 1.90 & .308 & 1 \\
\hline Educational programs & 1.45 & .686 & 5 & 2.05 & .887 & 1 & 1.80 & .410 & 2 \\
\hline Job Security & 1.45 & .686 & 5 & 1.40 & .503 & 6 & 1.75 & .444 & 3 \\
\hline IoT Regulations & 1.80 & .894 & 2 & 1.40 & .503 & 6 & 1.75 & .444 & 3 \\
\hline Standardization & 1.40 & .598 & 6 & 1.55 & .510 & 5 & 1.75 & .444 & 3 \\
\hline Economic collaborations & 1.55 & .686 & 4 & 1.70 & .470 & 3 & 1.65 & .489 & 4 \\
\hline Trust & 1.40 & .598 & 6 & 1.65 & .489 & 4 & 1.30 & .470 & 5 \\
\hline Knowledge sharing & 1.70 & .733 & 3 & 1.20 & .410 & 8 & 1.15 & .366 & 6 \\
\hline Organizational Culture & 2.00 & .918 & 1 & 1.35 & .489 & 7 & 1.10 & .308 & 7 \\
\hline Transparency & 1.45 & .605 & 5 & 1.95 & .510 & 2 & 1.05 & .224 & 8 \\
\hline $\begin{array}{l}\text { Total Number of } \\
\text { Respondents }\end{array}$ & \multicolumn{3}{|l|}{20} & \multicolumn{3}{|l|}{20} & \multicolumn{3}{|l|}{20} \\
\hline Kendall's W & \multicolumn{3}{|l|}{.115} & \multicolumn{3}{|l|}{.248} & \multicolumn{3}{|l|}{.479} \\
\hline
\end{tabular}

Table 8. Results of experts' opinions regarding the factors influencing the health of digital business ecosystem surrounding the IoT technology

\section{Discussion, Implications, Limitations, and Possible Future Research}

In this research, we conducted two panels of a Delphi study. In the first panel, we conducted interviews and in the second panel, we conducted a three-round study by distributing questionnaires. We conducted our study in two phases: during the first phase, we interviewed IoT experts working in IoT companies in Iran. During the second phase, we conducted a threeround Delphi study by distributing questionnaires among the IoT experts. Table 9 shows the convergence of the results from two phases. The main objective of this research is to extend 
the literature on the digital business ecosystem by exploring the health of the digital business ecosystem surrounding IoT technology, complex interactions of actors with unique roles, heterogeneous levels of control, and distinct degrees of interaction with the other actors of the ecosystem in Iran.

\begin{tabular}{|c|c|c|}
\hline Inquiries & First Panel ( Interviews) & Second Panel (Delphi Study) \\
\hline $\begin{array}{l}\text { Major } \\
\text { Actors }\end{array}$ & $\begin{array}{l}\text { Pseudo-private companies } \\
\text { (PPCs), start-ups, SMEs, } \\
\text { consumers, and the government }\end{array}$ & $\begin{array}{l}\text { Pseudo-private companies (PPCs), start-ups, SMEs, and the } \\
\text { government }\end{array}$ \\
\hline $\begin{array}{l}\text { Roles of } \\
\text { Major } \\
\text { Actors }\end{array}$ & $\begin{array}{l}\text { Dominator: Pseudo-private } \\
\text { companies (The B2G and B2B } \\
\text { market) } \\
>\quad \text { Niche Players: Start-ups, } \\
\text { SMEs dominating the B2C } \\
\text { market } \\
>\text { Keystone: Not detected }\end{array}$ & $\begin{array}{l}>\text { Dominator: Pseudo-private companies } \\
>\text { Niche: Start-ups } \\
>\text { Keystone: SMEs }\end{array}$ \\
\hline $\begin{array}{l}\text { Nature of } \\
\text { Interactions }\end{array}$ & $\begin{array}{l}>\quad \text { Most interaction with } \\
\text { financial entities and banks } \\
\text { PPCs have zero or little } \\
\text { interaction with the SMEs } \\
\text { and start-ups } \\
>\quad \text { The most interactions occur } \\
\text { among the PPCs, regulatory } \\
\text { bodies and the state } \\
>\quad \text { Lack of partnerships among } \\
\text { the actors }\end{array}$ & $\begin{array}{l}\text { No outcomes are expected from the relationships } \\
\text { between the PPCs and niche players; however, the } \\
\text { major outcome of relationships among the PPCs is } \\
\text { financial with banks and financial institutions. } \\
\text { Management is weak and inefficient and is based on } \\
\text { lobbying and favoritism }\end{array}$ \\
\hline $\begin{array}{l}\text { Health of } \\
\text { the } \\
\text { Ecosystem }\end{array}$ & $\begin{array}{l}\text { Lack of agility, volatility, and } \\
\text { fierce competition inside the } \\
\text { ecosystem due to the } \\
\text { dominance of PPCs } \\
>\quad \text { Lack of development of } \\
\text { digital business models and } \\
\text { reliance on legacy business } \\
\text { models } \\
\text { Lack of interest in developing } \\
\text { mechanisms of co-creating } \\
\text { products and services } \\
\text { specifically with consumers }\end{array}$ & $\begin{array}{l}\text { General Health Status: } \\
>\quad \text { Lack of continuous and consistent interaction among } \\
\text { the actors } \\
>\quad \text { Lack of continuous flow of knowledge among the } \\
\text { actors } \\
>\quad \text { Lack of encouraging environment for innovation and } \\
\text { creativity } \\
\text { Robustness (Consensus } 50 \%>\text { ) } \\
>\quad \text { The increasing number of successful IoT start-ups } \\
>\quad \text { Involvement of IoT actors in other business ecosystem } \\
>\quad \text { Changes in the IoT market share are dependent on the } \\
\quad \text { diffusion of innovation } \\
>\quad \text { Consumer experience is evolving in response to the } \\
\text { introduction of new technologies } \\
\text { Productivity (Consensus } 60 \%>\text { ) } \\
>\quad \text { There are relationships between the amount of labor } \\
\text { and capital employed and the additional value created } \\
>\quad \text { The productivity of firms is gradually improving } \\
>\quad \text { The members of the ecosystem can deliver innovation } \\
\text { capabilities with no restriction or barrier (consensus } \\
\text { 25\%) } \\
\text { Niche Creation (Consensus } 40 \%>\text { ) } \\
>\quad \text { The number of new options, technological building } \\
\text { blocks, categories, and products is varied } \\
\text { inside the ecosystem }\end{array}$ \\
\hline
\end{tabular}

Table 9. Comparisons of the results of the first panel and second panel 
As the study shows, there are two aspects of the digital business ecosystem around IoT in Iran: one ecosystem consists of only pseudo-private companies with strong interactions with government organizations and state-owned banks. The other digital business ecosystem surrounding IoT technology is composed of start-ups and private small and medium companies with no interaction with pseudo-private companies. The interaction between startups and SMEs is mainly with the universities. Most of the start-ups are located in the Science and Technology Parks of universities, and their funding is mainly from either private investors or universities. This shows that these two digital business ecosystems have not formed one unified collaborative network or modes of value-co-creation. As a result, in the Iranian context, due to the lack of collaborative and competitive interactions between the IoT pseudo-private companies and the IoT start-ups and SMEs, companies and individuals compete and cooperate in two separate digital business ecosystems and utilize their own common set of core assets.

The study shows that pseudo-private companies who have greater access to expanded networks of financial, social, knowledge and political resources control and dominate the B2G and B2B markets. Start-ups and SMEs have access to the B2C market, which owns a very small portion of the IoT market in Iran.

The nature of interactions in digital business ecosystems of IoT in Iran is mainly financial and the exchange of knowledge between the actors is minimal. This has impacted the development and competitive power of IoT start-ups. The paucity of knowledge exchange between actors is exacerbated by the shortage of valuable partnerships, which is one of the most effective strategies for developing the IoT market. The dearth of valuable collaborations adversely affects the ability of start-ups to increase the value of their products to target markets. The pseudo-private companies' lack of interest in establishing mechanisms for co-creating products and services with IoT start-ups is another roadblock preventing the distribution of the IoT value chain and increasing the centralized value chain managed and monitored by PPCs. The monopoly of pseudo-private companies on the B2G and B2B markets has also minimized agility, volatility, and fierce competition while weakening the competitiveness of start-ups. As a result, the environmental context for the growth of the digital business ecosystem surrounding IoT technology is deprived of valuable partnerships and collaborations, which is a major obstacle to cultivating a digital business ecosystem.

In summary, this study explores the digital business ecosystem of IoT in the context of a developing country. This study can therefore be used for further research on the business ecosystem of cutting-edge technologies in other developing countries, especially in contexts in which governments play a major role. This study has its own limitations, as most pseudoprivate companies declined to participate in our study. The other drawback of this analysis is that we have not interviewed government entities or international companies. One potential direction for future research is to involve more stakeholders to provide a more detailed and informative description of the digital business ecosystem surrounding IoT technology in Iran. Another possible line for future research is to study the business ecosystem of IoT in other contexts in which PPCs play a key role in the market growth of cutting-edge technologies to recognize similarities and differences between these contexts.

\section{References}

Adner, R. (2006). Match your innovation strategy to your innovation ecosystem. Harvard Business Review, 84(4), 98-107; 148. http://www.ncbi.nlm.nih.gov/pubmed/16579417 
Aksenova, G., Kiviniemi, A., Kocaturk, T., \& Lejeune, A. (2018). From Finnish AEC knowledge ecosystem to business ecosystem: lessons learned from the national deployment of BIM. Construction Management and Economics. https://doi.org/10.1080/01446193.2018.1481985

Chuang, M. Y. (2018). Association for Information Systems AIS Electronic Library (AISeL) Towards IoT Entrepreneurship: A Preliminary Investigation. MWAIS 2018 Proceedings, 36. http://aisel.aisnet.org/mwais2018/36

Corallo, A., Passiante, G., \& Prencipe, A. (2017). The Digital Business Ecosystem. Edward Elgar Publishing. https://dl.acm.org/citation.cfm?id=1534739

Financial Tribune. (2017). Iran Gov't Prioritizing Establishment of IoT Infrastructure. Financial Tribune. https://financialtribune.com/articles/economy-sci-tech/68116/iran-gov-tprioritizing-establishment-of-iot-infrastructure

Hein, A., Weking, J., Schreieck, M., Wiesche, M., Böhm, M., \& Krcmar, H. (2019). Value cocreation practices in business-to-business platform ecosystems. Electronic Markets. https://doi.org/10.1007/s12525-019-00337-y

Herweijer, C., Combes, B., Johnson, L., McCargow, R., Bhardwaj, S., Jackson, B., \& Ramchandani, P. (2018). Enabling a sustainable Fourth Industrial Revolution: How G20 countries can create the conditions for emerging technologies to benefit people and the planet. https://www.econstor.eu/handle/10419/177283

Iansiti, M., \& Levien, R. (2002). Keystones and dominators: Framing the operational dynamics of business ecosystems. In The Operational Dynamics of Business Ecosystems. https://pdfs.semanticscholar.org/8dcc/511cf90a76811107bf6c7757d8b630505e4b.pdf

Iansiti, M., \& Levien, R. (2004a). Strategy as Ecology. Harvard Business Review , March. https://hbr.org/2004/03/strategy-as-ecology

Iansiti, M., \& Levien, R. (2004b). The Keystone Advantage: What the New Dynamics of Business Ecosystems Mean for Strategy, Innovation, and Sustainability. https://www.hbs.edu/faculty/Pages/item.aspx?num=16920

Ikävalko, H., Turkama, P., \& Smedlund, A. (2018). Value Creation in the Internet of Things: Mapping Business Models and Ecosystem Roles. Technology Innovation Management Review, 8(3), 5-15. https://doi.org/10.22215/timreview/1142

Jónasdóttir, H., Dhanani, K., McRae, K., \& Mehnen, J. (2018). Upgrading Legacy Equipment to Industry 4.0 Through a Cyber-Physical Interface (pp. 3-10). Springer, Cham. https://doi.org/10.1007/978-3-319-99707-0_1

Kar, S., Chakravorty, B., Sinha, S., \& Gupta, M. P. (2018). Analysis of Stakeholders Within IoT Ecosystem (pp. 251-276). Springer, Cham. https://doi.org/10.1007/978-3-319-78378-9_15

Keil, M., Lee, H. K., \& Deng, T. (2013). Understanding the most critical skills for managing IT projects: A Delphi study of IT project managers. Information $\mathcal{E}$ Management, 50(7), 398414. https://doi.org/10.1016/J.IM.2013.05.005

Lee, G. (2019). What roles should the government play in fostering the advancement of the internet of things? Telecommunications Policy, 43(5), 434-444. https://doi.org/10.1016/J.TELPOL.2018.12.002 
Leminen, S., Rajahonka, M., Mika, W., \& Siuruainen, R. (2015). Ecosystem business models for the Internet of Things. Internet of Things Finland, 10(13). https://doi.org/10.13140/RG.2.1.4292.1126

Leminen, S., Westerlund, M., Rajahonka, M., \& Siuruainen, R. (2012). Towards IOT Ecosystems and Business Models (pp. 15-26). Springer, Berlin, Heidelberg. https://doi.org/10.1007/9783-642-32686-8_2

Linstone, H., \& Turoff, M. (1975). The delphi method. https://www.researchgate.net/file.PostFileLoader.html?id=563b341d5cd9e375988b45bc \&assetKey=AS\%3A292381292285964\%401446720541026

Mazhelis, O., Luoma, E., \& Warma, H. (2012). Defining an Internet-of-Things ecosystem. Lecture Notes in Computer Science (Including Subseries Lecture Notes in Artificial Intelligence and Lecture Notes in Bioinformatics), 7469 LNCS, 1-14. https://doi.org/10.1007/978-3-64232686-8_1

Moore, J. (1993). Predators and Prey: A New Ecology of Competition. Harvard Business Review . https://hbr.org/1993/05/predators-and-prey-a-new-ecology-of-competition

Moore, J. (1996). The death of competition : leadership and strategy in the age of business ecosystems. Wiley Harper Business. https://lib.ugent.be/catalog/rug01:000431120

Pan, J.-S., Chen, S.-M., \& Nguyen, N. T. (Computer scientist). (2012). Intelligent information and database systems : 4th Asian Conference, ACIIDS 2012, Kaohsiung, Taiwan, March 19-21, 2012, Proceedings. Part II. Springer.

Paré, G., Cameron, A.-F., Poba-Nzaou, P., \& Templier, M. (2013). A systematic assessment of rigor in information systems ranking-type Delphi studies. Information $\mathcal{E}$ Management, 50(5), 207-217. https://doi.org/10.1016/J.IM.2013.03.003

Rong, K., Hu, G., Lin, Y., Shi, Y., \& Guo, L. (2015). Understanding business ecosystem using a 6C framework in Internet-of-Things-based sectors. International Journal of Production Economics, 159, 41-55. https://doi.org/10.1016/J.IJPE.2014.09.003

Rong, K., Shi, Y., \& Yu, J. (2013). Nurturing business ecosystems to deal with industry uncertainties. Industrial Management $\mathcal{E}$ Data Systems, 113(3), 385-402. https://doi.org/10.1108/02635571311312677

Saheb, T., \& Izadi, L. (2019). Paradigm of IoT big data analytics in the healthcare industry: A review of scientific literature and mapping of research trends. Telematics and Informatics. https://doi.org/10.1016/J.TELE.2019.03.005

Selander, L., Henfridsson, O., \& Svahn, F. (2010). Transforming Ecosystem Relationships in Digital Innovation. International Conference on Information Systems. http://www.divaportal.org/smash/record.jsf?pid=diva2\%3A390104\&dswid=3642

Selander, L., Henfridsson, O., \& Svahn, F. (2013). Capability Search and Redeem across Digital Ecosystems. Journal of Information Technology, 28(3), 183-197. https://doi.org/10.1057/jit.2013.14

Senyo, P. K., Liu, K., \& Effah, J. (2019). Digital business ecosystem: Literature review and a framework for future research. International Journal of Information Management, 47, 52-64. https://doi.org/10.1016/J.IJINFOMGT.2019.01.002 
Shin, D. (2019). A living lab as socio-technical ecosystem: Evaluating the Korean living lab of internet of things. Government Information Quarterly, 36(2), 264-275. https://doi.org/10.1016/J.GIQ.2018.08.001

Sun, L., Tan, C., Robertson, S., Liu, K., Cook, M., \& Collins, C. (2016). Open Digital Business Ecosystems: A Pathway for Value Co-creation (pp. 85-94). https://doi.org/10.1007/978-3-31942102-5_10

Sun, Q., Wang, C., Zuo, L., \& Lu, F. (2018). Digital empowerment in a WEEE collection business ecosystem: A comparative study of two typical cases in China. Journal of Cleaner Production, 184, 414-422. https://doi.org/10.1016/J.JCLEPRO.2018.02.114

The Mobile Economy: Middle East and North Africa 2018. (2018). www.gsmaintelligence.com

von der Gracht, H. A. (2012). Consensus measurement in Delphi studies: Review and implications for future quality assurance. Technological Forecasting and Social Change, 79(8), 1525-1536. https://doi.org/10.1016/J.TECHFORE.2012.04.013

Westerlund, M., Leminen, S., \& Rajahonka, M. (2014). Designing Business Models for the Internet of Things. In Technology Innovation Management Review (Vol. 4, Issue 7). Talent First Network. https://timreview.ca/article/807

Copyright: (C) 2021 authors. This is an open-access article distributed under the terms of the Creative Commons Attribution-NonCommercial 3.0 Australia License, which permits noncommercial use, distribution, and reproduction in any medium, provided the original author and AJIS are credited.

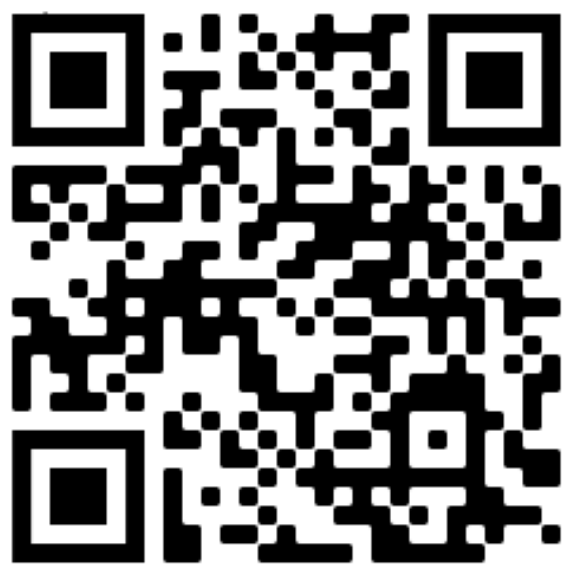

